\title{
The first earthworm collections from Nicaragua with description of two new species (Oligochaeta)
}

\author{
EMMA SHERLOCK ${ }^{1}$, STEWART LEE ${ }^{2}$, SALLY MCPHEE ${ }^{2}$, MARK STEER ${ }^{2}$, \\ JEAN MICHEL MAES ${ }^{3} \&$ CSABA CSUZDI ${ }^{4}$ \\ ${ }^{\prime}$ Department of Zoology, Natural History Museum London \\ ${ }^{2}$ The Society for Environmental Exploration, 50-52 Rivington Street, London \\ ${ }^{3}$ Entomological Museum, Leon, Nicaragua \\ ${ }^{4}$ Hungarian Natural History Museum and Systematic Zoology Research group of HAS
}

\begin{abstract}
In August 2009 the Natural History Museum London, Hungarian Natural History Museum and Systematic Zoology Research group, Entomological Museum in Leon and The Society for Environmental Exploration, mounted the first earthworm collection expedition to Nicaragua. No native earthworm species had previously been recorded for this country. This paper lists 18 new species records for the Country with the description of two new taxa to science: Eutrigaster (Graffia) azul sp. n. and Eutrigaster (Graffia) nicaraoi sp. n. New data on the species Eutrigaster (Eutrigaster) oraedivitis Cognetti, 1904 is also presented here.
\end{abstract}

Key words: Earthworms, Nicaragua, Eutrigaster, new species

\section{Introduction}

Knowledge of the Latin American earthworm fauna is currently patchy. Some countries such as Brazil and Ecuador have, to some extent, been sampled; the species total for Brazil currently stands at 305, that for Ecuador and Columbia at 139 (Brown \& Fragoso, 2007). By contrast the earthworm assemblages of other South American countries such as Uruguay and Paraguay are virtually unknown.

To date, the study of the diversity, range and ecology of earthworms has been largely neglected across all of the Central American countries. Prior to this paper, a mere 96 species records existed collectively for the whole of Central America. The least studied country of which being Nicaragua. In fact not one native species record existed for this country, the only records coming from specimens seized at customs in the 1960's, 1970's and 1980's (Gates $1965,1972,1982)$. This amounted to two species records and one generic record, all of which were peregrine species: Pontoscolex corethrurus (Müller, 1857), Drawida barwelli (Beddard, 1886) and a Dichogaster sp.

For such an important animal group this is a huge omission, especially as neighbouring countries in South America are known to have a rich and diverse fauna (Brown \& Fragoso 2007).

In August-September 2009 The Natural History Museum in London, The Society for Environmental Exploration London, The Hungarian Natural History Museum and The Entomological Natural History Museum in Nicaragua embarked on a short project to produce the first meaningful earthworm species records for Nicaragua.

Some additional material from Rio San Juan collected in 2007 by Hungarian Natural History Museum's scientists Dr. O. Merkl, N. Balint and T. Németh was donated to the authors and is also included.

\section{Material and methods}

In each locality sampled, a north south orientated transect, consisting of 3 equidistant slabs of soil (mon), were dug. Each slab measured $30 \mathrm{~cm}$ x $30 \mathrm{~cm}$ x $20 \mathrm{~cm}$, and the soil was hand sorted for worms. A microhabitat (micro) search 